\title{
Giant paraesophageal hiatal hernia: A complex clinical entity
}

\author{
Farzaneh Banki, MD
}

\footnotetext{
From the Department of Surgery, McGovern Medical School at UTHealth; and the Esophageal Disease Center, Memorial Hermann Southeast, Houston, Tex.

Disclosures: Author has nothing to disclose with regard to commercial support.

Received for publication April 8, 2017; accepted for publication April 12, 2017; available ahead of print June 2, 2017.

Address for reprints: Farzaneh Banki, MD, Professor, Department of Surgery, McGovern Medical School at UTHealth, Director of Esophageal Disease Center, Memorial Hermann Southeast, 11800 Astoria Blvd, Houston, TX 77089 (E-mail: Farzaneh.Banki@uth.tmc.edu).

J Thorac Cardiovasc Surg 2017;154:752-3

$0022-5223 / \$ 36.00$

Copyright $(5) 2017$ by The American Association for Thoracic Surgery

http://dx.doi.org/10.1016/j.jtcvs.2017.04.037
}

In their article in this issue of the Journal, "Prospective Study of Giant Paraesophageal Hernia Repair with 1-Year Followup," Stringham and colleagues ${ }^{1}$ provide an important addition to the literature for the management of a challenging and complex clinical entity. The strengths of the article include its prospective nature, the high percentage of patients who concluded the study, and its overall design with regard to assessment of symptomatic and radiographic recurrence.

In addition, the study reports the surgical results of different operative repairs by the laparoscopic and open approaches (left thoracotomy and laparotomy) and includes the first-time and reoperative procedures. Stringham and colleagues ${ }^{1}$ consider a recurrent hiatal hernia as any herniation of the stomach above the diaphragm, and they compare the symptomatic and radiographic recurrences in patients with recurrent hiatal hernia smaller than $2 \mathrm{~cm}$ and $2 \mathrm{~cm}$ or larger by using imaging and a validated preoperative and postoperative questionnaire.

The rate of radiographic recurrence after laparoscopic repair of giant paraesophageal hiatal hernia is reported to be $12 \%$ to $16 \% .^{2,3}$ Most previous studies defined recurrence as hiatal hernia $2 \mathrm{~cm}$ or larger, mentioned by Stringham and colleagues" as "conventionally defined recurrence." The rate of recurrence was nearly doubled when all the "radiographic recurrences," including hiatal hernias smaller than $2 \mathrm{~cm}$, were included $(18.8 \%$ vs $32.7 \%$ ). It is reported that most patients with radiographic recurrence are asymptomatic. ${ }^{3,4}$ The results of the study demonstrate that quality of life and patient satisfaction are negatively affected by a hiatal hernia of any size. This is the key point of the article-the emphasis that any recurrent hiatal hernia, as small as it may be, should be carefully assessed and not underestimated.

Collis gastroplasty was used to treat $66 \%$ of the patients in this series. Similarly, Collis gastroplasty has been reported in $40 \%$ to $56 \%{ }^{2,5}$ of primary laparoscopic giant paraesophageal hiatal hernia repairs. The use of an esophageal lengthening procedure may be subjective and driven by the surgeon's training and institutional hernia.

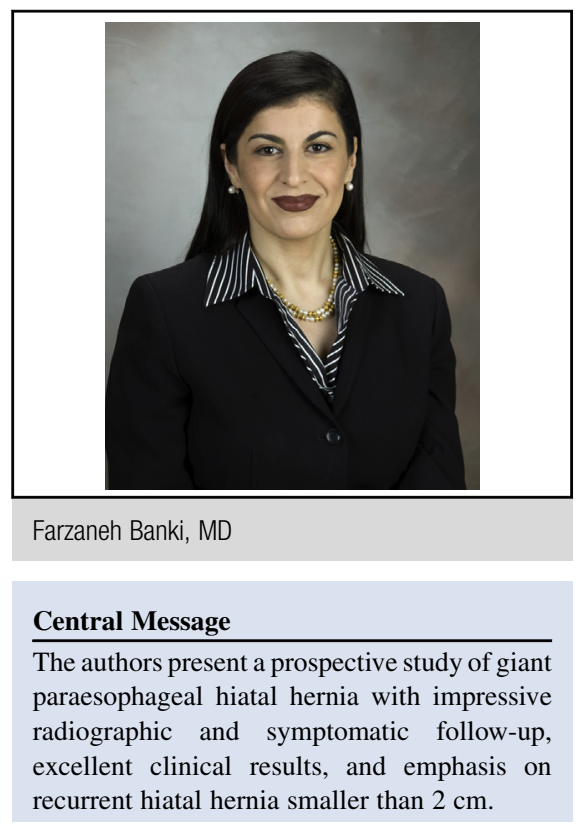

See Article page 743

tradition. In a review of 662 patients, the use of Collis gastroplasty was shown to have decreased from $86 \%$ to $53 \% .^{3}$ Esophageal stricture is regarded as the most common predictor of esophageal shortening, followed by long-segment Barrett esophagus. ${ }^{6}$ It would be informative to identify the rates of stricture and Barrett esophagus in the patients in this series for better delineation of the need for Collis gastroplasty.

This study included 7.5\% recurrent paraesophageal hiatal hernias. The reoperative procedures could be studied separately, because they present a much more challenging technical problem, with longer operative time and higher rates of intraoperative and postoperative complications. Stringham and colleagues ${ }^{1}$ have the expertise to repair giant paraesophageal hernias through both open and laparoscopic approaches. It would be beneficial to compare the outcomes of laparoscopic versus open procedures to assess any advantages of each approach.

This excellent prospective study with assessment of symptomatic and radiographic recurrence at 1 year, with focus on symptoms and the quality of life of patients with recurrent hiatal hernias smaller than $2 \mathrm{~cm}$, provides an important additional clinical tool for understanding the treatment of patients with giant paraesophageal hiatal 


\section{References}

1. Stringham JR, Phillips JV, McMurry TL, Lambert DL, Jones DR, Isbell JM, et al. Prospective study of giant paraesophageal hernia repair with 1 year follow-up. $J$ Thorac Cardiovasc Surg. 2017;154:743-51.

2. Zehetner J, Demeester SR, Ayazi S, Kilday P, Augustin F, Hagen JA, et al. Laparoscopic versus open repair of paraesophageal hernia: the second decade. J Am Coll Surg. 2011;212:813-20.

3. Luketich JD, Nason KS, Christie NA, Pennathur A, Jobe BA, Landreneau RJ, et al. Outcomes after a decade of laparoscopic giant paraesophageal hernia repair. $J$ Thorac Cardiovasc Surg. 2010;139:395-404.

4. Rathore MA, Andrabi SI, Bhatti MI, Najfi SM, McMurray A. Metaanalysis of Recurrence After Laparoscopic Repair of Paraesophageal Hernia. JSLS. 2007; 11:456-60.

5. Pierre AF, Luketich JD, Fernando HC, Christie NA, Buenaventura PO Litle VR, et al. Results of laparoscopic repair of giant paraesophageal hernias: 200 consecutive patients. Ann Thorac Surg. 2002;74:1909-15; discussion 1915-6.

6. Gastal OL, Hagen JA, Peters JH, Campos GM, Hashemi M, Theisen J, et al. Short esophagus: analysis of predictors and clinical implications. Arch Surg. 1999;134: 633-6; discussion 637-8. 